\title{
PRINCIPLES AND FUNCTIONS OF MANAGEMENT OF PRODUCTION CAPACITY
}

Tursunov Bobir Ortikmirzaevich

Tashkent State University, Economic University, Tashkent, Republic of Uzbekistan tursunov-bobir@mail.ru

\section{Professional Paper doi:10.5937/jouproman5-15248}

\begin{abstract}
The principles and functions of managing the production capacity are discussed in the article. On the part of the author, general and particular principles of managing the production capacity are classified, and another special principle of managing production capacity is proposed. The document more describes the management approach required for the Capacity Planning and Management, rather than going into the technical details. As such, it does not assume detail technical knowledge or go into the mathematical basis for performance modelling or testing.
\end{abstract}

Keywords: production, principles, functions of managing the production capacity, coordination.

\section{Introduction}

Production capacity is determined by the power of the leading shops, units or sites. The leading shops, sites or units are understood as those from them where the main and most mass technological operations on production of finished (main) product are carried out and in which the prevailing part of the equipment is concentrated. Definition of concrete values of production capacity in the textile enterprises is carried out on each production facility taking into account the planned actions. On power of the leading group of the equipment the production capacity of the site, on the leading site the production capacity of the shop, on the leading shop - the production capacity of the textile enterprise is installed.
Production capacity depends on many factors, for example technical, social, economic, organizational. In science and in practice allocate the maximum, theoretical, economic, practical capacities. It is necessary to emphasize that the gained wide circulation and recognition both in domestic, and in foreign literature of a method of calculation of production capacity of the enterprise, shops, the site are founded or on the principle of the direct account, or on the principle of optimization of loading of the equipment with the help linearly - program model. Calculations on their basis are carried out for current (annual, quarter) production planning. Information used for this purpose is not only significantly aggregated, but also does not consider discretization of engineering procedure, its recurrence of objects of the labor from one production operation to another. In other words, the difficult multioperating dynamic system which the production based on discrete technology is is reduced to significantly simplified, static, represented one (leader) or several groups of the equipment, system, information on which is provided only by the located and necessary funds of machine time. 


\section{Methodology}

The most famous great contribution to the research and definition of the theory of control of production capacity was made by foreign scientists as C. J. McNair and Richard Vangermeersch, their published book named "Total Capacity Management: Optimizing at the Operational, Tactical, and Strategic Levels" is still in high demand.

The production capacity of the enterprise is characterized by the maximum quantity of products of the appropriate quality and assortment that can be produced by it in a unit of time with the full use of the basic production assets in the optimal operating conditions. The production capacity of a textile enterprise is characterized by the maximum quantity of products of the appropriate quality and assortment that can be produced by it in a unit of time with the full use of fixed production assets in optimal operating conditions.

\section{Body}

In the world economic science the concept of "productive capacity" has developed quite a long time ago. Most economists consider production capacity as a complex system concept, and interpret different ways of managing production capacity in modern conditions.

It is also methodologically important to take into account that production capacity is formed and used in the process of purposeful organizational and managerial activity. Therefore, modern management, both corporate, and industry, and nationwide in particular, should consider production capacity as one of its basic functions.
Taking into account the above, it can be concluded that the management of production capacity should have a comprehensive, scientifically-based approach.

Capacity management is the implementation of several interrelated functions: analysis of the use of production capacity, estimation of the quantity and technical level of equipment, planning of development of production capacity, motivation and control.

Function analysis of the use of production capacity. The optimal level of production capacity and increased efficiency of using these capacities is the main task of managing production capacity in the present period. From the solution of this problem depends the place of the enterprise in the pre-production, the way out of the crisis, its financial condition, competitiveness in the market. The production capacity is the result of the activity of all structural divisions of the enterprise, i.e. It is integrative in nature, reflecting both the quantitative and qualitative aspects of one hand - all involved in production resources, including labor, management, etc., on the other hand, it is characterized by the product of labor: its volume, level of costs and quality, Production capacity directly affects the competitiveness of products and shapes the competitive advantages of the enterprise. Therefore, the analysis of production capacity should be based on marketing approaches, in particular SWOT analysis, BCG matrices, McKinsey. 
Analysis subfunction - estimation of quantity and technical level of equipment. Strict competition requires a constant review of the current technology in the direction of increasing the share of modern and high-performance equipment that ensures the growth of labor productivity and the reduction of current costs by reducing the material and energy intensity of the products. The gap in technical capabilities between new and old models that continue to be used is constantly increasing. The improvement of the qualitative composition of the park depends on how objectively designed and quickly implemented the plan of organizational and technical measures for the active replacement of physically worn out and obsolete equipment.

The main processes involved in capacity management are shown in Figure 1. The "Evaluate Risk" process has been placed in the centre, since it drives the need for the other major processes. To be able to evaluate the risk, however, requires a level of knowledge about the system to be deployed, and its likely usage. It is for this reason that the other processes exist.

A quick summary of each of the processes is:

\section{Table-1}

Main processes involved in capacity management ${ }^{2}$

\begin{tabular}{|l|l|}
\hline \multicolumn{1}{|c|}{ Process } & \multicolumn{1}{c|}{ Description } \\
\hline Estimate Volumes & $\begin{array}{l}\text { The performance of any complex system is directly } \\
\text { dependent on the load placed on the system, and the volume } \\
\text { of data within it. Thus it is necessary to have an idea of the } \\
\text { load that will be placed on the system, which should be in } \\
\text { terms relevant to the business application of the system. It is } \\
\text { important to include in this investigation the variation with } \\
\text { time of the system's use. Flat usage profiles just don't happen. }\end{array}$ \\
\hline Investigate Technology & $\begin{array}{l}\text { To manage capacity it is important to understand what you } \\
\text { are managing the capacity of. You need to understand what is } \\
\text { under your control and what is not, and to have an idea of } \\
\text { how all the components of the system will react at different } \\
\text { load levels. }\end{array}$ \\
\hline Evaluate Risk & $\begin{array}{l}\text { Understand what might go wrong in the system as a whole, } \\
\text { and what the impact of this happening would be. Capacity } \\
\text { Management, in common with most management activities, } \\
\text { is often simply a case of trading off the risks that exist until } \\
\text { areasonable way forward is decided on }\end{array}$ \\
\hline Performance Model & $\begin{array}{l}\text { To manage the performance and risk of the system you need } \\
\text { to understand it. You need to be able to understand how }\end{array}$ \\
\hline
\end{tabular}

\footnotetext{
${ }^{2}$ Source: White Paper: The Principles of Capacity Management.Sarquol Limited 2006.
} 


\begin{tabular}{|l|l|}
\hline & $\begin{array}{l}\text { variation in the volumes of the system will affect the end } \\
\text { users. You need to be able to understand how this can be } \\
\text { offset by scaling the size of different components within the } \\
\text { system. To do this there are two approaches, do it in reality } \\
\text { or model the system and try it out with a model. I would } \\
\text { recommend always starting with some form of model }\end{array}$ \\
\hline Build and Test & $\begin{array}{l}\text { In the end you will need to have a system and to test the } \\
\text { system against the required volumes. The "Build" here } \\
\text { should be read as all forms of coding, configuration, tuning } \\
\text { and optimisation. It includes activities such as optimising } \\
\text { database indices, and adding new hardware. The testing is the } \\
\text { application of load testing tools in a development system, as } \\
\text { well as production monitoring systems }\end{array}$ \\
\hline Manage Service Level & $\begin{array}{l}\text { It is important to understand the level of performance that is } \\
\text { considered "necessary and sufficient." Testing, adding } \\
\text { hardware and optimisation are important, time consuming } \\
\text { and expensive processes. The Service Level for a system } \\
\text { should define the agreed volumes over time and the } \\
\text { acceptable performance for those volumes. The operational } \\
\text { system must then be tested against this agreement on an } \\
\text { ongoing basis. The Service level agreement must take } \\
\text { account of the statistical nature of performance management. } \\
\text { Thus a statement such as "All operations must complete is } \\
\text { less than } 2 \text { seconds" is insufficient. It could be improved by } \\
\text { stating "For all critical operations they must be completed } \\
\text { from initiation by the user to the system result being visible } \\
\text { in 2s for 95\% of cases." The level of certainty required is as } \\
\text { important as the figure chosen. In both cases choosing more } \\
\text { stringent criteria is likely to result in more hardware and } \\
\text { development costs. }\end{array}$ \\
\hline
\end{tabular}

Once the system is in production the Capacity Management starts to gather information from the actual system in operation. It is not unlikely that actual user behaviour will bear little resemblance to that predicted in the formal testing. Some agility may, therefore, be needed during the production operation. The management of the system's capacity becomes "business as usual" but must not stop. If the capacity is not monitored and managed then long-term performance problems will be the result.
Function of planning the development of production capacity. It is based and follows from the selected enterprise development strategy and production capacity management strategy, which will be discussed below. Usually the implementation of the task of further intensification of production is carried out through technical development plans that are part of the business plan of the enterprise and must be linked to other sections. 
These plans are developed in accordance with the scientific and technical policy of a particular enterprise in two main areas:

- increasing the level of competitiveness of products;

- improvement of the technical base of production.

In a market economy characterized by fierce competition, the commodity producer must constantly monitor the level of progressiveness of the production process and product quality. Ensuring an appropriate level of competitiveness of production can not be achieved without improving the existing technology or developing a new one. These vectors are determined by the production capacity strategy and its appearance.

The motivation function is the process of motivating other people to work to achieve the organization's goals. In fulfilling this function, the head of the production capacity management subsystem implements the material and moral stimulation of the employees on whom the planning and use of production capacity primarily depends and creates the most favorable conditions for the manifestation of their abilities and professional "growth". With good motivation, the organization's personnel perform their duties in accordance with the goals of this organization and its plans. The process of motivating the management of production capacity involves creating the possibility for workers to meet their needs, provided that they properly fulfill their duties.

The function of monitoring the effectiveness of management of production capacity. The main objects of operational control of production are many planning and economic indicators: from hourly or shift-day assignments to annual production volumes. The operational accounting and control of the fulfillment of production production plans should contribute to the correct solution of such current tasks as ensuring rhythmic work in all parts of production, reducing breaks in the movement of objects of labor in separate technological stages, increasing the flexibility of current production and sales plans taking into account the dynamic changes in market requirements etc.

We have refined the general and particular principles of managing the production capacity, which are given in Table-1. 
Principles of production capacity management

\begin{tabular}{|c|c|}
\hline $\begin{array}{l}\text { General principles of production } \\
\text { capacity management }\end{array}$ & $\begin{array}{l}\text { Particular principles of managing the } \\
\text { production capacity }\end{array}$ \\
\hline $\begin{array}{l}\text { Scientific; } \\
\text { Systematic, complex; } \\
\text { Proportionality; } \\
\text { Continuity; } \\
\text { Flexibility; } \\
\text { Allocation of the main link; } \\
\text { Time factor accounting; } \\
\text { Combinations of strategic and tactical } \\
\text { approaches; } \\
\text { Combinations of market and planned approaches. }\end{array}$ & $\begin{array}{l}\text { Accounting of the type, form and method of organization } \\
\text { of production; } \\
\text { Proportionality of the components of the process chain; } \\
\text { Allocation of bottleneck; } \\
\text { Production capacity planning based on the life cycle of } \\
\text { business units; } \\
\text { Application of marketing approaches, including demand } \\
\text { forecasts, SWOT-analysis of BKG matrices, McKinsey. }\end{array}$ \\
\hline
\end{tabular}

Source:Classified and compiled by the author.

The scientific principle assumes that the management of production capacity must be carried out on a scientific basis, i.e. On reliable information in scientifically based methods. In addition, this principle means that the management of production capacity should use the latest achievements of science and technology, as well as advanced methods of managing the production capacity of individual enterprises known in the world.

The principle of continuity lies in the fact that the management of the production capacity at the enterprise must be carried out continuously, without interruptions, and be iterative in nature.

The principle of flexibility is based on the prerequisites that necessitate the principle of continuity: the uncertainty and variability of the external environment and the firm's changing of its own assessments, its positions and intentions. In this case, the principle of flexibility is to give management of production capacity the ability to change its direction in connection with the occurrence of unforeseen changes of internal or external nature. To implement the required flexibility, management of production capacity must be carried out in such a way that it is possible to make necessary changes to it, linking them to changing conditions. Thus, the flexibility of managing the production capacity gives additional stability to the enterprise itself, and to those programs, plans that are implemented on it.

The principles of unity, complexity, coordination and coordination are closely linked. Their joint use presupposes a complex, systemic nature of the process of managing the production capacity. The unity of the management of production capacity follows from the integrative nature of the phenomenon of production capacity itself and presupposes the obligatory mutual coordination and coordination of the planned activities of the individual departments of the enterprise and plans of various levels. 
From this point of view, production capacity management the enterprise must cover all its production units in order to ensure a balance between them. This applies to the formation of technological chains that determine the production capacity.

The principle of validity of objectives and focus on the final result of the activity assumes that, based on the systemic nature of the management of production capacity, all segments of the enterprise have a single ultimate goal, the implementation of which is at the heart of the matter is given priority. At the same time, it is always necessary to choose the leading links at the enterprise, from the implementation of which depends, first of all, the final result, which is indicated in the strategy, and strive to realize them in the first place. The choice of leading links should be based on a deep analysis of the state of affairs in the enterprise and the factors that most significantly affect the production capacity.

As for the particular principles of managing the production capacity, the first three are sufficiently well known and described in the special literature.

We propose to supplement them with such principles as accounting of the life cycle of a business unit. In other words, capacity planning should be based on existing business units and the choice of those that will be most promising in the future in terms of demand. To analyze them, you need to use methods: marketing analysis SWOT, McKinsey, PIMS and others. This is the next private principle of managing production capacity.

Business unit (business unit, BU, $\mathrm{CXE})$ is a legally structured, organizationally separated subsidiary, in relation to the parent company structure, a division of the company significant enough for the business to have its own strategy outlined from the company's overall strategy. The business unit is fully or partially economically separate, responsible for a particular type of activity. Often, the goals and objectives of the business model correlate with the goals and objectives of the parent company, but may differ radically. Business units are accountable directly to the top management of the company. Large multibrand, holding, diversified in the areas of companies achieve a synergistic effect due to the formation of cohesive, one-time managerial teams, supporting business enthusiasm and entrepreneurship. This effect is achieved by working in strategic business units - SBU (strategic business unit). Management of the business unit is carried out by dedicated management, led by the head of the business unit. The functioning within the framework of an independent unit allows the head of the business unit to concentrate on the goals, quickly and adequately respond to the changing needs of the customers and the situation on the market, develop the skills and experience of the staff. This is an absolute advantage of segmenting the big business of the parent company into a business unit.

\section{Conclusion}

Managing production capacity is very important in achieving the organization's long-term success. The production capacity is formed and used in the process of purposeful organizational and managerial activity. Therefore, modern management, both corporate, and industry, and nationwide in particular, should consider as one of its basic functions of managing production capacity. Capacity management is the realization of several interrelated functions: analysis of the use of production capacity, estimation of the quantity and technical level of equipment, planning of development of production capacity, motivation, control. 
As mentioned above, planning is an essential function of managing production capacity. It can be strategic and operational: the character. The implementation of the task of further intensification: production is carried out through technical development plans. These plans are developed in accordance with the scientific and technical policies of a particular enterprise in two main areas:

- increasing the level of competitiveness of products;

- improvement of the technical base of production;

Competitiveness of products is, relative characteristics, including a set of technical and economic indicators that reflect the interests of consumers: (product price, productivity, operating costs, etc.). Planning the development of the technical base of any production includes the development of a set of organizational and technical measures aimed at introducing progressive methods of manufacturing products and ensuring the growth of competitiveness as a result of improving the quality of the product, reducing machine capacity (labor intensity), material intensity, cost, etc.

References

[1] N. Douglass (1994). "Economic Performance through Time," American Economic Review, 84(3), pp. 359-368.

[2] R.B.Chase. (1981). The Customer Contact Approach to Services: Theoretical Bases and
Practical

Extensions.https://doi.org/10.1287/opre.29.4 .698. Published Online: August 1.

[3] Bunich P.G. Actual issues of efficient use of production capacities and fixed assets / P.G. Bunich. M .: Economizdat, 1963.- 69 p.

[4] Vodyanov A. (2006). Production capacities of Russian industry in the context of economic growth problems / A. Vodyanov, O. Gavrilova, T. Marshova // Russian Economic Journal. No. 2.

[5] Petrovich I.M. (2002). Production capacity and economy of the enterprise.

[6] Fathutdinov, R.A. (2001). Organization of production: textbook / R.A. Fatkhutdinov, M .: Infra-M.

[7] Vasilevich L.P. (1985). Perfection of methods for planning the development of production capacities. Candidate dissertation. Leningrad.

[8] Balabin A.A. (1991). Modeling reserves of production capacity. Candidate dissertation. Novosibirsk.

[9] Privalov V.N. (2005). "Organizational and economic support of increasing the efficiency of using the production potential of textile equipment" Ph.D thesis. Kostroma.

[10]Zabaykin Yu.V. (2006). "Improving the organization of production at textile enterprises" Ph.D. thesis. Moscow.

[11] Kaparova NB (2007). "Multilevel system of increasing the efficiency of knitted production" Ph.D. thesis. St. Petersburg.

[12] S.S.Gulyamov. (2006). Economic of organization, Taskent. 335pp.

[13] Sh.Zainutdinov. (2004). Theory of management, Taskent. 614pp.

[14] N.K.Yuldashev. (2012). Organization management, Taskent. $246 \mathrm{pp}$. 